\title{
ACUTE HEMOLYTIC ANEMIA FROM THE SULFONAMIDES
}

\author{
By CHARLES L. FOX, JR. ${ }^{1}$ AND REUBEN OTTENBERG \\ (From the Department of Bacteriology, College of Physicians and Surgeons, Columbia \\ University, and the Medical Service, Mount Sinai Hospital, New York City)
}

(Received for publication April 16, 1941)

Within the past year we have seen 9 cases of acute hemolytic anemia in the course of sulfanilamide or sulfapyridine therapy, with 6 deaths. In the hope of explaining the mechanism of this hemolysis, the laboratory studies which form the basis of this report were conducted in 4 cases. The hemoglobin derivatives in serum, erythrocytes and urine were examined by the recording photoelectric spectrophotometer. The high degree of accuracy obtainable with this objective method permitted comparison of the hemoglobin derivatives in the serum derived from destroyed red cells with those in the cells that remained intact. The new blood pigment, methemalbumin, recently described by Fairley (1), was detected in the plasma. The findings are reported and interpreted in relation to the mechanisms of hemolysis, hemoglobinuria and hemolytic shock.

\section{Clinical data (cases listed in order of increasing severity)}

Case 1, P. P. (Number 459109), negro, age 32, was under treatment for infected bite of the hand. The Wassermann reaction was positive. He received 24 grams of sulfanilamide in 4 days. On the morning of the fifth day, intense hemoglobinuria occurred and jaundice was noted. The hemoglobin concentration of the blood, not measured heretofore, dropped from 75 per cent (Salhi) on the morning of the fifth day to 60 per cent at 4 p.m. At this time the highly colored specimens of plasma and urine to be discussed below were obtained; his icterus index was 38 and his blood urea $\mathrm{N}$ 16. The blood picture was that of hemolytic anemia, with 11 per cent reticulocytes; there was no sickling. The hemoglobinuria lasted about 36 hours. The urine showed occasional granular casts but no red blood cells. There were no further symptoms; sulfanilamide therapy was stopped, the jaundice continued for $\mathbf{4}$ days and the patient recovered.

Case 2, J. M. (Number 454755), Italian, male, age 43, was admitted with severe erysipelas of the face 48 hours after puncture of a sinus for suppurative ethmoiditis. He received a total of 12 grams of sulfanilamide during 2 days. On the second day he was observed to be jaundiced (icteric index 33) and there was shock tenderness over

\footnotetext{
1 Aided in part by the Dazian Foundation.
}

the liver. Blood hemoglobin was 104 per cent (Sahli); the blood culture was sterile, and the blood sulfanilamide level was $4.0 \mathrm{mgm}$. per cent. On the third day, although the erysipelas appeared to be controlled, the temperature rose to $103.6^{\circ} \mathrm{F}$. The urine at this time contained bilirubin but no hemoglobin. On the fourth day, the jaundice appeared deeper and the blood hemoglobin had fallen to 75 per cent. On the fifth day a paroxysm of hemoglobinuria occurred accompanied by severe nausea, vomiting, abdominal and lumbar pain and tenderness. The urine showed large amounts of hemoglobin but no red blood cells. The blood hemoglobin fell to 34 per cent with 1.8 million red blood cells; the cell volume was 16 per cent. The white blood cells rose from 16,000 to 25,000 . The platelets were normal. Blood smears showed 9 per cent myelocytes, 8 per cent normoblasts, and 8 per cent reticulocytes. The icteric index rose to 108 , blood cholesterol was $205 \mathrm{mgm}$. per cent with cholesterol esters reduced to $70 \mathrm{mgm}$. per cent. The patient appeared very ill but was not in collapse. Transfusion of 1 liter of blood was given and, in order to induce excretion of an alkaline urine, $4000 \mathrm{cc}$. of Hartman's solution and glucose and saline solutions were administered daily. As a result there was a copious diuresis- $8000 \mathrm{cc}$. during the 2 days of hemoglobinuria. On the sixth day, the patient was still in great discomfort; the icteric index was 90 , hemoglobinuria was still present though less marked, and another transfusion of $500 \mathrm{cc}$. of blood was given. On the seventh day, the patient's condition was better; the hemoglobinuria ceased, jaundice and bilirubinuria were still present. From this point on the patient, after two additional blood transfusions, gradually recovered.

Case 3, B. E. (Number 462878), a physician, age 39, had an infection at the tip of his nose. He took a few doses of sulfanilamide and the local condition cleared up. After one or two days, however, he continued to have some fever and, as some râles were heard at the base of the left lung, he took sulfapyridine, a total of only 11 grams in 2 days. At the end of this time he suddenly became very acutely ill with high fever, extreme pallor, profound jaundice and great prostration. Hemoglobin was noted to have fallen from 80 to 40 per cent and his white blood count rose from 12,000 to 50,000 . On admission to the hospital his blood pressure was $128 / 70$. His spleen and liver were greatly enlarged. His urine was Burgundy red; microscopically it showed casts and occasional red blood cells.

He was given a transfusion of $500 \mathrm{cc}$. at once and 600 cc. the next day; his hemoglobin rose to 67 per cent. At this time his blood urea was found to be $69 \mathrm{mgm}$. per 
cent and his blood carbon dioxide combining power was 33 volumes per cent. The blood sulfapyridine 24 hours after sulfapyridine therapy had been stopped was still $7.4 \mathrm{mgm}$. per cent. There was a moderate degree of oliguria, although there was never complete suppression of urine; during the 2 days before his death he secreted $1650 \mathrm{cc}$. of urine. There was a steadily progressive rise of temperature until $107^{\circ} \mathrm{F}$. was reached. This was accompanied by increasing shock. A sample of his blood plasma taken the last day of his life (the third day after the onset of the hemolytic anemia) still was nearly black.

Postmortem examination showed, besides a bronchopneumonia, the characteristic findings of acute hemolysis: icterus, marked edema of the liver with striking enlargement of the Kupffer cells which contained nuclear debris and red blood cells. The liver cells themselves were not diffusely damaged, but scattered small foci of four or five necrotic liver cells were present; these might have been caused by small capillary blockages due to Kupffer cell proliferation (Dr. Klemperer). The spleen weighed 480 grams; it showed a tremendous degree of active hyperemia and for practical purposes was indistinguishable from a spleen of hemolytic icterus. The kidneys showed an immense number of hemoglobin casts, chiefly in the deeper tubules and Henle's loops.

Case 4, I. L., the father of a doctor, a man age 63, never seriously ill before, developed bronchial pneumonia. No sputum was obtained; blood culture was negative. He was given 5 grams of sulfanilamide the first day and then 12 grams of sulfapyridine during the following 2 days. Because of the onset of severe vomiting, cyanosis, and weakness, the sulfapyridine was stopped. Twentyfour hours later it was noted that the urine was of mahogany color and there was severe deep lumbar pain. At this time the pulse rate and the blood pressure, which had been normal, underwent a sudden change; the pulse rose to 138 and the blood pressure became unobtainable; the patient was obviously in shock. The blood showed a hemoglobin of 50 per cent, with red cell count of only $1,000,000$. This discrepancy was explained, however, when the blood plasma was obtained, since it was almost black. The white blood count was 32,000 , the platelets 400,000; the blood smear showed 10 per cent myelocytes and 13 nucleated red blood cells per 100 white blood cells. The urine microscopically showed no red blood cells but much amorphous deposit. Urine secretion gradually diminished during 24 hours until it ceased altogether. The total amount of urine in the last 2 days of life was approximately $1500 \mathrm{cc}$. The jaundice first noticed on the fourth day after beginning of medication became deeper and the urea nitrogen of the blood rose to $42 \mathrm{mgm}$. per $100 \mathrm{cc}$. In spite of three transfusions of $500 \mathrm{cc}$. each, which brought the red cell count to 2,000,000 and the blood pressure to $134 / 84$, the pallor and collapse continued and the patient died on the fifth day after the onset of his pneumonia, about 48 hours after onset of the hemolytic shock.

\section{METHODS}

Urine and plasma 2 were examined directly, diluting when necessary for accuracy. Red cells from citrated blood were washed three times with physiological salt solution, suspended in $\mathrm{M} / 100$ phosphate buffer, $\mathrm{pH} 6.9$, and laked with saponin. For identification and definite detection of small amounts of abnormal pigments, ordinary spectroscopy with recognition of absorption bands is inadequate. Only careful spectrophotometric determination of light absorption at each wavelength followed by observations of changes in light absorption after the addition of various chemicals gives reliability to the findings.

For this purpose two instruments were used: (1) a photoelectric spectrophotometer with a Lange galvanometer, ${ }^{3}$ and (2) the Hardy recording spectrophotometer. 4 Transmission curves of all solutions were made before and after addition of neutral 5 per cent sodium cyanide solution. In the figures, only the significant parts of the curves are shown.

Methemoglobin was estimated by the change in optical density at wavelength $630 \mathrm{~m} \mu$ by the formula: 5

$$
\begin{aligned}
& \text { Optical density } \lambda 630 \mathrm{~m} \mu \text { Optical density } \lambda 630 \mathrm{~m} \mu \\
& \text { (initial) - (after } \mathrm{CN} \text { ) } \\
& =\text { grams methemoglobin } \\
& \text { per } 100 \text { cc. }
\end{aligned}
$$

Total hemoglobin was measured in those specimens containing only hemoglobin and methemoglobin by the

${ }^{2}$ Specimens were examined as soon as obtained. In some instances urines were examined after standing overnight. Controls, however, of hemoglobin added to urine showed that under these conditions only a little of the hemoglobin is converted into methemoglobin; serum when kept in the icebox remains unchanged overnight. On account particularly of the marked effect of $\mathrm{pH}$ on the absorption band of methemoglobin (9) it is important to note that all solutions except some sera were diluted before spectroscopy with $M / 100$ phosphate buffer solution of $\mathrm{pH}$ 6.9. When sera were used undiluted they were fresh and it was believed they were adequately buffered. Red cells were diluted one hundred times; urines were diluted five to twenty-five times.

${ }^{3} \mathrm{We}$ are profoundly indebted to Dr. Bruce Hogg of the Department of Surgery, College of Physicians and Surgeons, Columbia University, who set up the apparatus (2) and performed some of the first tests for us (3).

4 This is an entirely automatic instrument which records a continuous curve at all visible wavelengths with no personal equation whatever (4). For its use we wish to thank the Electrical Testing Co., York Ave., New York, and the American Cyanamid Co., Stamford, Conn.

5 This formula was obtained by previous studies (5) using the Hardy spectrophotometer and differs from that of Drabkin and Austin (9) in that the maximum absorption of methemoglobin is located at $\lambda 630 \mathrm{~m} \mu$ instead of $\lambda 634 \mathrm{~m} \mu$ (See also Michel (6).) 
TABLE I

The approximate distribution of blood pigments in the surviving red cells, serum, and urine of 4 cases of acute hemolytic anemia

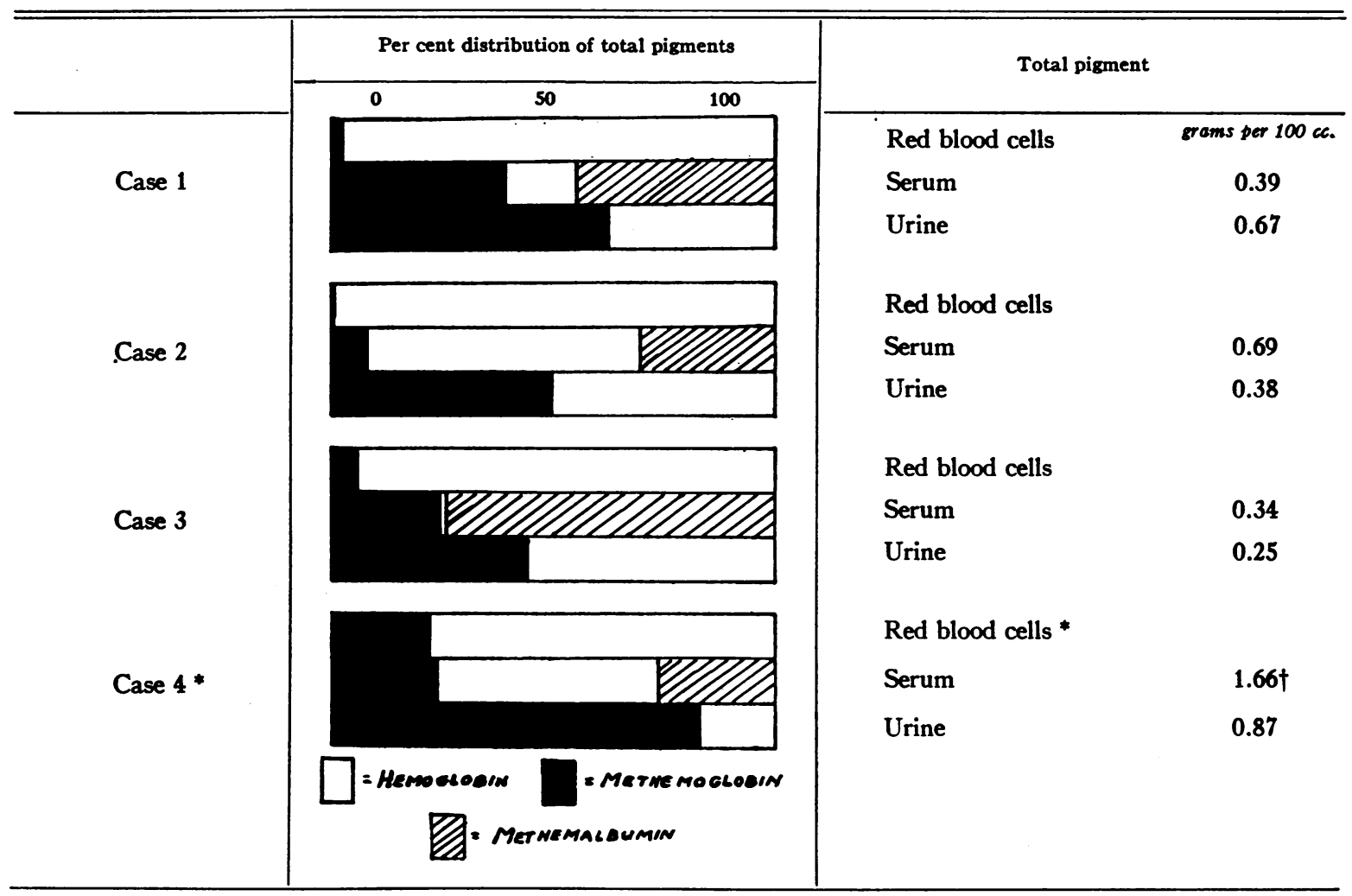

* Red blood cells of this patient contained 4 per cent sulfhemoglobin.

† By iron method 2.00 grams per cent.

method of Stadie (7). This converts oxyhemoglobin to methemoglobin by means of potassium ferri-cyanide and then changes the methemoglobin to cyanmethemoglobin by means of cyanide. Specimens of plasma containing sulfhemoglobin or methemalbumin (which does not combine with cyanide) cannot be measured in this way, and in the fourth case the total was measured by the alpha alpha' dipyridyl iron method (8).

The method used for determination of the new pigment methemalbumin in the serum will be discussed under the caption "Results-Sera."

\section{RESULTS}

Red blood cells. In the figures are shown the relevant portions of the spectrophotometric curves of the washed, laked erythrocytes of the $4 \mathrm{pa}$ tients. The curves of the first 2 are smooth with no indentation or band to indicate any abnormal pigment. Upon addition of cyanide, however, there is a small decrease in the optical density, indicating the presence of a proportionately small amount of methemoglobin. On calculation the amounts of methemoglobin in these cases (Table I) are found to be small enough to escape detection by ordinary methods. The third and fourth cases, however, which were fatal, showed a larger amount of methemoglobin with an absorption band at $\lambda 630 \mathrm{~m} \mu$ which was dispersed with cyanide.

Unfortunately, at the time we knew of no such combined chemical-optical method for the quantitative measure of sulfhemoglobin. ${ }^{\circ}$ But it may be pointed out that, since the absorption band of sulfhemoglobin at $\lambda 620 \mathrm{~m} \mu$ is nearly three times as intense as that of methemoglobin at $\lambda 630 \mathrm{~m} \mu$, similar small amounts of sulfhemoglobin if present would have produced a detectable indentation of the transmission curve after cyanide at $\lambda 620$ $\mathrm{m} \mu$. Such a very small deviation is actually shown in Case 4. It may be stated, therefore,

- Fairley's observation that $\mathrm{H}_{2} \mathrm{O}_{2}$ obliterates the absorption band of sulfhemoglobin at $\lambda 620 \mathrm{m \mu}$ provides such a method for the future (1). 


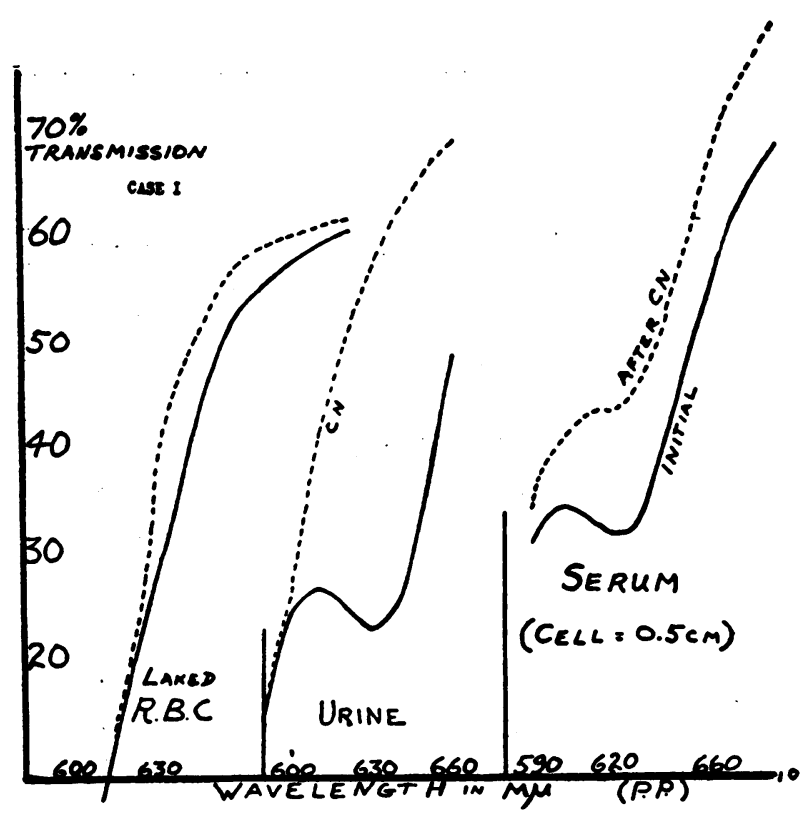

Patient 1

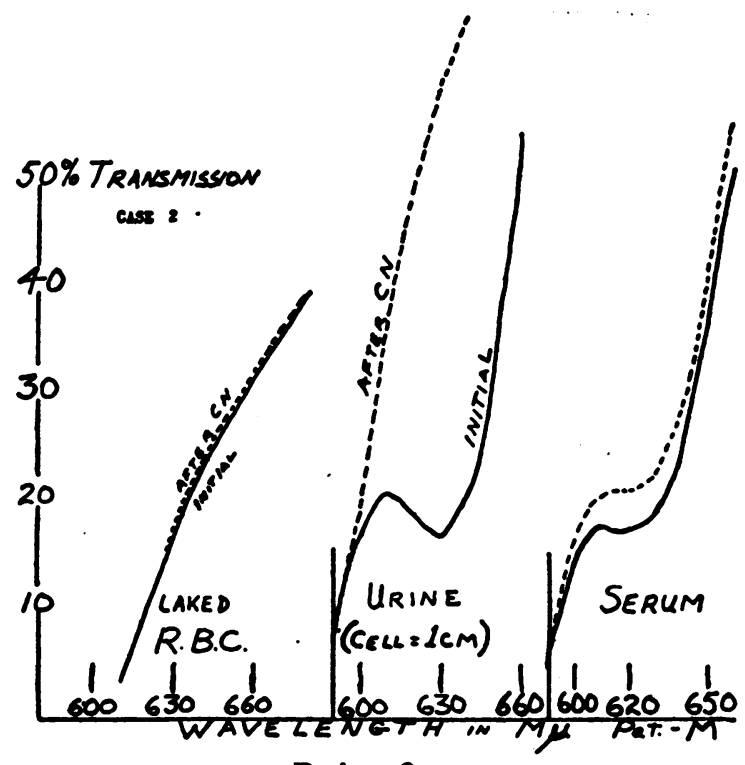

Patient 2

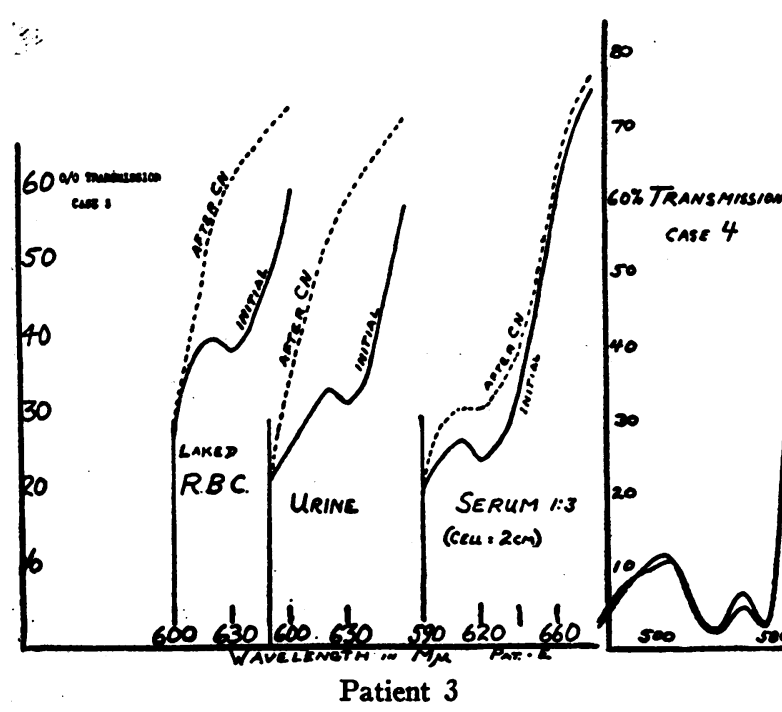

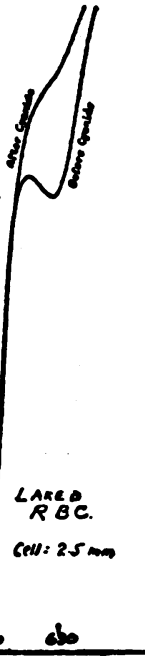

Patient

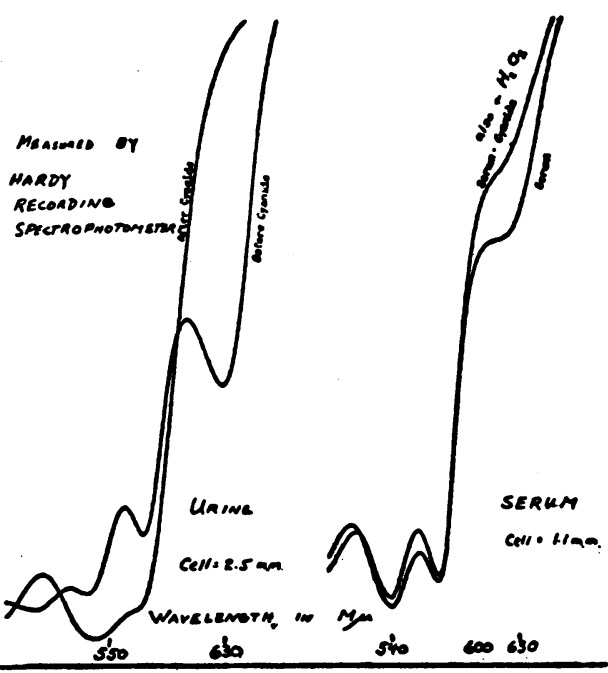

4. Hardy Recording Spectrophotometer curves from $\lambda 500$ to $\lambda 700 \mathrm{~m} \mu$

Fig. 1. Spectrophotometric Curves of Laked Red Blood Ceils, Urine, and Serum of 4 Cases of Acute Hemolytic Anemia

Ordinates $=$ per cent transmission Abscissae $=$ wavelengths

that (except for Case 4) erythrocytes of these patients contain no detectable sulfhemoglobin.

Urines. The spectrophotometric curves of the urines of these patients are different from those of the red blood cells in one important regard. There is a sharp peak of light absorption pre- $\longrightarrow=$ initial curve

$-\ldots+-\ldots=$ curve after cyanide cyanide, this peak disappears completely and the resulting curve is quite smooth. This is characteristic of large amounts of methemoglobin admixed with hemoglobin; and, on calculation, the percentages of methemoglobin range from 44 to 
83 per cent of the total blood pigments present in the urine (Table I). The location of the sharp peak at $\lambda 630 \mathrm{~m} \mu$ and the disappearance of this absorption band, leaving a smooth curve after the addition of cyanide, prove the absence of sulfhemoglobin and methemalbumin from the urine.

Sera. The sera of these patients are quite different. Instead of a smooth curve or a sharp absorption peak, they show a broad band of absorption extending from $\lambda 610 \mathrm{~m} \mu$ to $\lambda 640 \mathrm{~m} \mu$. On analysis by the addition of cyanide, the curve does not become smoothed out as in the case of the urine. The absorption in the region of the red is decreased and measurement of the density change at $\lambda 630 \mathrm{~m} \mu$ permits computation of the amount of methemoglobin present (Table I). The cyanide-resistant broad band centered at $\lambda 620$ $\mathrm{m} \mu$ is indicative of the simultaneous presence of still another pigment. Since sulfhemoglobin has its characteristic absorption at $\lambda 620 \mathrm{~m} \mu$, we at first attempted to ascribe this absorption to sulfhemoglobin. Computations using Austin and Drabkin's absorption coefficients (9), however, did not fit the observed data. We then became aware of Fairley's discovery in the plasma of blackwater fever of a new pigment, methemalbumin, which also has an absorption band in this region (1). The absorption band of this pigment, like that of sulfhemoglobin, is not obliterated by cyanide. These pigments can be differentiated from each other, however, by the addition of $\mathrm{H}_{2} \mathrm{O}_{2}$ which causes the disappearance of the band of sulfhemoglobin at $\lambda 620 \mathrm{~m} \mu$ but does not disturb the band of methemalbumin.

The unique finding in all the sera was the presence of a broad band about $\lambda 620 \mathrm{~m} \mu$ not obliterated by cyanide. In the fourth case, this was further tested with 3 per cent hydrogen peroxide but no change in the light absorption occurred. This proved the presence of methemalbumin and the absence of sulfhemoglobin.

In order to determine methemalbumin quantitatively, this pigment was prepared by incubating sterile normal plasma with hemoglobin at $37^{\circ} \mathrm{C}$. for 4 weeks. The absorption spectrum was determined as described elsewhere (10). With the absorption coefficients so obtained, the amounts of hemoglobin and of methemalbumin could then be calculated from the observed data at the peak wavelengths $\lambda 540 \mathrm{~m} \mu$ and $\lambda 620 \mathrm{~m} \mu$ by solving two simultaneous equations ${ }^{7}$ of the following general form:

Optical density observed minus absorption due to methemoglobin ${ }^{8}=$ absorption due to hemoglobin plus absorption due to methemalbumin.

$$
\begin{aligned}
& \text { O.D.620 - concentration } \mathrm{MHb} \times \text { coefficient } \\
& =\text { concentration } \mathrm{Hb} \times \text { coefficient } \mathrm{Mb}_{620}+\text { con- } \\
& \text { centration MetAlb }
\end{aligned}
$$$$
\times \text { coefficient } \text { MetAlb }_{\mathbf{6 2 0}} \text {. }
$$

The total blood pigments would naturally be the sum of the concentrations of methemoglobin, hemoglobin and methemalbumin (Table I). In the fourth case this was checked independently by iron determination and a reasonably close correspondence was obtained, the difference presumably representing iron already freed in bilirubin formation.

The results of these examinations compiled in Table I indicate that, after an acute hemolytic episode, the surviving red blood cells are essentially normal or contain but little methemoglobin, far less than plasma and urine. In addition, the plasma contains a third pigment, methemalbumin, which is readily formed in the plasma from extracorpuscular hemoglobin.

In Table II are shown the total amount of hemoglobin liberated (E) and the amount liberated in relation to patients' weight $(G)$, the plasma level of hemoglobin at a variable number of hours after the onset of hemolysis $(\mathrm{H})$, the amount of hemoglobin remaining in the circulating plasma at this time (I), the total hemoglobin excreted $(\mathrm{J})$, and the relation of this to the hemoglobin

\footnotetext{
7 This procedure has been used satisfactorily heretofore, e.g., $(5,10,11)$. The validity of this method might be questioned in dealing with mixtures that might contain other unrecognized pigments. Lemberg (12) has described pigments formed by the disintegration of hemoglobin but their characteristics are not such as to be confused with methemalbumin. In the serum of Case 3 , in which there was practically no hemoglobin remaining, the concentration of methemalbumin was calculated directly from the residual absorption at $\lambda 620 \mathrm{m \mu}$ after cyanide (10). The concentration found was $0.258 \mathrm{gram}$ per cent as against 0.263 gram per cent by simultaneous equations.

8 Methemoglobin determined independently by change in density at $630 \mathrm{~m} \mu$ after addition of cyanide.
} 
TABLE II

Removal of hemoglobin liberated by hemolysis

\begin{tabular}{|c|c|c|c|c|c|c|c|c|c|c|c|}
\hline \multirow{4}{*}{$\begin{array}{c}\text { A } \\
\text { Case } \\
\text { number }\end{array}$} & \multirow{3}{*}{\multicolumn{2}{|c|}{$\begin{array}{c}\text { B } \\
\begin{array}{c}\text { Red blood cell } \\
\text { counts }\end{array} \\
\text { Hemolysis }\end{array}$}} & \multirow{4}{*}{$\begin{array}{c}\text { C } \\
\text { Hemo- } \\
\begin{array}{c}\text { globin** } \\
\text { liber- } \\
\text { ated }\end{array}\end{array}$} & \multirow{4}{*}{$\begin{array}{c}\text { D } \\
\text { Blood } \\
\text { volumet }\end{array}$} & \multirow{4}{*}{ 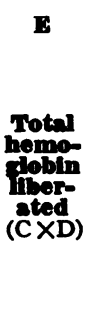 } & \multirow[t]{2}{*}{$\mathbf{F}$} & \multirow[t]{2}{*}{ G } & \multirow[t]{2}{*}{$\mathbf{H}$} & \multirow{4}{*}{ 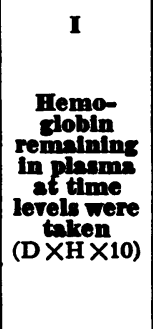 } & J & $\mathbf{K}$ \\
\hline & & & & & & & & & & \multicolumn{2}{|c|}{ Hemoglobinuria } \\
\hline & & & & & & $\begin{array}{c}\text { Patient's } \\
\text { weight }\end{array}$ & $\begin{array}{l}\text { globin } \\
\text { liberated }\end{array}$ & $\begin{array}{l}\text { Terel of } \\
\text { total }\end{array}$ & & \multirow{2}{*}{$\begin{array}{c}\text { Totel } \\
\text { exereted }\end{array}$} & \multirow{2}{*}{ 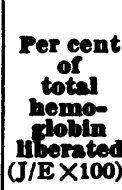 } \\
\hline & Before & After & & & & & & & & & \\
\hline & \multicolumn{2}{|c|}{ millions } & $\begin{array}{c}\text { grams per } \\
\text { liter of } \\
\text { blood }\end{array}$ & liters & grams & $\mathrm{kgm}$. & $\begin{array}{c}\text { grams per per } \\
\text { kilo of } \\
\text { weeigh }\end{array}$ & $\begin{array}{l}\text { grams per } 100 \\
\text { cc. }\end{array}$ & grams & grams & \\
\hline $\begin{array}{l}1 \\
2 \\
3 \\
4\end{array}$ & $\begin{array}{l}5.0 \\
5.5 \\
5.0 \\
4.5\end{array}$ & $\begin{array}{l}3.0 \\
1.8 \\
2.0 \\
1.0\end{array}$ & $\begin{array}{r}62 \\
115 \\
94 \\
109\end{array}$ & $\begin{array}{l}7.9 \\
6.6 \\
6.2 \\
7.0\end{array}$ & $\begin{array}{l}490 \\
760 \\
583 \\
763\end{array}$ & $\begin{array}{l}90 \\
75 \\
70 \\
80\end{array}$ & $\begin{array}{r}5.5 \\
10.1 \\
8.1 \\
9.5\end{array}$ & $\begin{array}{l}0.39(0.22) \ddagger \\
0.69(0.49) \\
0.34(0.08) \\
1.66(1.22)\end{array}$ & $\begin{array}{r}23 \\
39 \\
17 \\
104\end{array}$ & $\begin{array}{r}14 \\
24 \\
5 \\
12\end{array}$ & $\begin{array}{l}\mathbf{3} \\
\mathbf{3} \\
\mathbf{1} \\
\mathbf{2}\end{array}$ \\
\hline $\begin{array}{l}48 \mathrm{~A} \\
48 \mathrm{~B} \\
50\end{array}$ & & & & & $\begin{array}{l}6.2 \\
8 . \\
7.3\end{array}$ & & $\begin{array}{l}0.102 \\
0.24 \\
0.10\end{array}$ & $\begin{array}{l}0.25 \\
0.32 \\
0.25\end{array}$ & & $\begin{array}{l}0 \\
0.4 \\
0.6\end{array}$ & $\begin{array}{l}\overline{5} \\
8\end{array}$ \\
\hline
\end{tabular}

* Estimated on basis of 5,000,000 red blood cells per cmm. and corresponds to 15.6 grams hemoglobin per $100 \mathrm{cc}$. blood (Haden).

$\dagger$ Calculated as 8.8 per cent patient's weight.

\$ The figures in parenthesis () represent the excretable pigments hemoglobin and methemoglobin.

liberated $(\mathrm{K})$. Since plasma volumes could not be measured, the estimations in columns $\mathrm{C}, \mathrm{D}, \mathrm{E}$, $\mathrm{G}, \mathrm{I}, \mathrm{K}$ are, of course, only approximate. For comparison, similar data are added for 3 cases selected from a previous study (13) in which measured amounts of hemoglobin were injected intravenously in normal human beings. Here $E$ represents the grams of hemoglobin injected, and the plasma levels $(\mathrm{H})$ are those noted at once after injection.

\section{DISCUSSION}

While the objective of finding the cause of the hemolysis was not attained, the observations permit certain deductions as to (1) mechanism of hemolysis, (2) disposal of hemoglobin and (3) cause of death.

\section{(1) Mechanism of hemolysis}

Fairley's demonstration (1) that methemalbumin is formed in vitro and in vivo from extracorpuscular blood pigments in human serum is evidence that the methemalbumin in the present case was secondary to the hemolysis and was not directly mediated by the sulfonamides. It apparently does not play a rôle in the mechanism of hemolysis. Sulfhemoglobin may also be excluded since none was found (except 4 per cent in the cells of Case 4).

The occurrence of large proportions of methemoglobin in the serum with less in the intact red blood cells suggests the possibility that it was the red blood cells containing methemoglobin which underwent hemolysis. ${ }^{9}$ This might indicate that formation of methemoglobin in the red blood cells was an etiological factor. Inasmuch as methemoglobin is formed from hemoglobin only by oxidizing agents (e.g., ferricyanide), the uniform occurrence of some methemoglobin in the red cells of all patients treated with the sulfonamide drugs $(3,14)$ is excellent evidence that the body produces oxidizing agents from these drugs (15). Furthermore, one such oxidant, hydroxylaminobenzene sulfonamide, unlike ferricyanide, can penetrate the erythrocyte membrane and is detectable in the urine during sulfanilamide therapy (16). The contrast between the frequency of methemoglobin in the red blood cells and the infrequency of hemolytic anemia shows that, al-

${ }^{9}$ It is not certain, however, how much of the methemoglobin in the serum was present in the red blood cells before hemolysis; some may have been formed after hemolysis by the unknown oxidant. 
though oxidizing agents are usually formed, they per se are not hemolytic. Furthermore, if the usual oxidation products were hemolytic, one would of necessity expect that hemolysis would parallel methemoglobin formation. This is not the case. Most patients receiving huge doses over long periods of time with correspondingly large amounts of methemoglobin in their cells (up to 40 per cent in man (14), 75 per cent in monkeys (17)), do not develop hemolysis. On the other hand, when hemolytic anemia occurs, it appears early-within 2 to 5 days from the start of administration, and after only moderate doses of the drug (only 12 grams in one of the present cases). Accordingly, it is possible that certain individuals form unusual oxidation products which are hemolytic and which are present in or affect chiefly the red cells containing methemoglobin. For example, the nitro compound representing a further stage of oxidation of the amino group of sulfanilamide than the hydroxylamine is more toxic as well as more bacteriostatic (18). Presumably, this peculiarity is permanent for the individual, for in 3 out of 4 patients who once suffered acute hemolytic anemia from sulfanilamide, readministration of the drug a year later again induced this syndrome and on the identical day (19).

It has been stated that a " transient but striking increase of fragility to sodium chloride in $\mathbf{5}$ cases of severe sulfanilamide hemolytic anemia" was a preliminary stage in hemolysis (20). The absence of increased fragility, on the other hand, in 3 cases studied after the hemolysis had been completed (21) is explicable by our finding that the red blood cells not hemolyzed were relatively normal, i.e., free of methemoglobin; this suggests that the fragility reported only lasts until the already damaged red blood cells have been laked.

It is possible, also, in view of the peculiar timing and small inciting dosage, that this syndrome is the result of drug allergy. Landsteiner (22) has shown that antibodies may be produced after sensitization with many drugs chemically linked to proteins, and this has recently been carried out with the sulfonamides (23). None of the other drugs known to cause drug allergy, however, produces hemolytic anemia. Furthermore, drug fever and skin rashes, complications of sulfonamide therapy more readily attributable to drug allergy, are not associated with hemolytic anemia.

\section{(2) Disposal of hemoglobin; hemoglobinuria, bilirubin formation}

In the previous study of the renal threshold in man (13), hemoglobin levels of 0.32 gram per 100 cc. were obtained immediately after intravenous injection of 8 grams of hemoglobin. Removal of the hemoglobin from the circulation was very rapid, being complete in all cases at 12 hours. In the hemolytic anemia cases the amounts of hemoglobin liberated were 50 to 100 times greater (495 to 763 grams). If the acute hemolysis occurred at one time, the initial levels of hemoglobin would have ranged around 10 grams per $100 \mathrm{cc}$. of plasma. The actual levels, 1.66 to 0.34 gram per cent found 12 to 48 hours later, show how rapid must have been the removal of the huge amounts of hemoglobin.

A surprisingly small proportion of all this hemoglobin was excreted ${ }^{10}$; in the experiments, never more than 8 per cent of the amount injected; in the hemolysis cases, not over 4 per cent of the amount liberated. This does not point to a renal threshold (25) with excretion of all hemoglobin above some given plasma level.

What happens to the retained hemoglobin? Some is obviously transformed almost at once to bilirubin. The intense and prompt jaundice ${ }^{11}$ shown by all the patients may reasonably be attributed to overloading of the liver by the bilirubin produced suddenly from several hundred grams of hemoglobin. The normal liver excretes in 24 hours an amount of bilirubin derivable from destruction of about $121 / 2$ grams of hemoglobin (27) but is known to have considerable reserve capacity (28). The previous experimental injection of amounts up to 8 grams of hemoglobin produced scarcely measurable increases in blood bilirubin (13); injections of amounts up to 16 grams produced slight bilirubinemia (29). That the jaundice is due to the excess of bilirubin rather

10 Many cases of hemolytic anemia have gross hematemesis and melena (24). It is not known whether this represents excretion of hemoglobin or actual hemorrhage.

11 Every 100 grams of hemoglobin may be converted to 4 grams of bilirubin. Certain tissues absorb large amounts of bilirubin in excess of their water content (26). 
than liver damage is shown by the minor liver changes at autopsy (our Case 3 and (30)) and by the prompt disappearance of jaundice in those cases which recover. This contrasts with the marked liver damage in the non-hemolytic type of sulfonamide jaundice (31).

\section{(3) Cause of death}

Renal blockage due to obstruction of the tubules by precipitated hemoglobin is frequently stated to be the cause of death in hemoglobinuria (32). De Navasquez (33) has recently restudied this question. His analysis of human and animal material does not support the view that simple mechanical blockage of the renal tubules is an adequate explanation. Suppression of urine occurred in several of our cases (not those detailed in this report) and one of them had anuria for 24 hours, but none of them died of it. When death follows from renal insufficiency in hemoglobinuria, it is caused by uremia and occurs at a much later date.

Anuria or oliguria can be caused by shock, and our severe cases were in shock. The cause of shock from hemolysis is unknown. Attempts to detect a high degree of toxicity in dissolved red cells themselves have failed. ${ }^{12}$ Laked red cells are relatively innocuous (although most of the experiments on this point have been done with doses proportionately far smaller than the huge mass of cells dissolved in the present cases). Potassium from dissolved red cells has been suggested as the toxic agent (34) but the symptoms of potassium poisoning are different from those of hemolytic shock.

In experimental hemoglobinemia (13), and in the present cases (Table II), the products of hemolysis disappear with extraordinary rapidity from the circulation. The red cells normally constitute 45 per cent of the blood volume. The destruction and removal of $2 / 3$ of the original number of red cells with the resulting 30 per cent reduction in blood volume might be a contributory factor in producing shock.

Reviewing the course of the severest cases, it is apparent that transfusion was of no great benefit,

\footnotetext{
12 Two hundred cc. of pooled blood of dogs was laked with distilled water and centrifuged. The sedimented stroma was resuspended and injected intravenously into a normal dog. No toxicity resulted.
}

possibly because of further hemolysis of the new blood. Plasma transfusion would be free of this danger.

\section{SUMMARY}

The acute hemolytic anemia of sulfanilamide and sulfapyridine therapy was studied in 4 cases, two of them fatal.

Those erythrocytes which survived hemolysis, the serum (which contained the products of hemolysis), and the urine were examined by the objective photoelectric spectrophotometer.

The red cells that survived hemolysis were essentially normal, containing little methemoglobin or sulfhemoglobin. The serum 12 to 48 hours after onset of hemolysis contained 0.4 to 1.7 grams per $100 \mathrm{cc}$. of three blood pigments, hemoglobin, methemoglobin and, contrary to expectation, not sulfhemoglobin, but Fairley's new pigment, methemalbumin. This pigment was then prepared according to Fairley's technic of incubating human plasma with hemoglobin, and a method for its measurement is described. No evidence was found for its involvement in the hemolytic process; it was not excreted in the urine.

The relation of methemoglobin and hemolysis to oxidation products of the sulfonamides is discussed.

Approximate calculation was made of the amounts of hemoglobin liberated in these explosive hemoglobinemias. Comparison with the small amounts left in the circulation after 12 to 48 hours, and the still smaller amounts (4 per cent or less) excreted by the kidneys, shows that the body has means of removing rapidly from the plasma some 500 to 700 grams of hemoglobin without the aid of renal excretion.

Shock was a prominent symptom most marked in the fatal cases. The hemolyzed cells in these cases represented about 30 per cent of the total blood volume. This much reduction in blood volume following the demonstrated rapid removal of the products of hemolysis from the circulation may be a factor in the explanation of hemolytic shock.

\section{BIBLIOGRAPHY}

1a. Fairley, N. H., A new blood pigment: Pseudo-methaemoglobin. Nature, 1937, 139, 588. 
b. Idem, Methaemalbumin (pseudo-methaemoglobin). Ibid., 1938, 142, 1156.

c. Idem, The spontaneous disintegration of certain blood pigments, with special reference to methaemalbumin formation. Brit. J. Exper. Path., 1940, 21, 231.

2. Chargaff, E., Ziff, M., and Hogg, B., The reaction between cephalin and hemoglobins. J. Biol. Chem., 1939, 131, 35.

3. Fox, C. L., Jr., Hogg, B., and Ottenberg, R., The occurrence of methemoglobinemia during therapy with sulfapyridine, sulfathiazole, and sulfamethylthiazol: Formation of methemoglobin in vitro. J. Clin. Invest., 1940, 19, 792.

4. Hardy, A. C., A new recording spectrophotometer. J. Optic. Soc. America, 1935, 25, 305.

5. Fox, C. L., Jr., and Cline, J. E., The occurrence of methemoglobinemia during sulfanilamide therapy. J. Clin. Invest., 1940, 19, 123.

6. Michel, H. O., A study of sulfhemoglobin. J. Biol. Chem., 1938, 126, 323.

7. Stadie, W. C., A method for the determination of methemoglobin in blood. J. Biol. Chem., 1920, 41, 237.

8. Coombs, H. I., Studies of the haemoglobin and iron of the blood. I. The determination of the total iron of blood. Biochem. J., 1936, 30, 1588.

9a. Drabkin, D. L., and Austin, J. H., Spectrophotometric studies. II. Preparations from washed blood cells; nitric oxide hemoglobin and sulfhemoglobin. J. Biol. Chem., 1935, 112, 51.

b. Austin, J. H., and Drabkin, D. L., Spectrophotometric studies. III. Methemoglobin. J. Biol. Chem., 1935, 112, 67.

10. Fox, C. L., Jr., The spectrophotometry of methemalbumin. J. Clin. Invest., 1941, 20, 603.

11. Junowicz-Kocholaty, R., and Hogness, T. R., The spectroscopic determination of cytochrome $C$ and its distribution in some mammalian tissue. J. Biol. Chem., 1939, 129, 569.

12. Lemberg, R., Legge, J. W., and Lockwood, W. H., Coupled oxidation of ascorbic acid and haemoglobin. Biochem. J., 1939, 33, 754.

13. Ottenberg, R., and Fox, C. L., Jr., The rate of removal of hemoglobin from the circulation and its renal threshold in human beings. Am. J. Physiol., 1938, 123, 516.

14. Harris, J. S., and Michel, H. O., The formation of methemoglobin and sulfhemoglobin during sulfanilamide therapy. J. Clin. Invest., 1939, 18, 507.

15. Fox, C. L., Jr., The significance of the oxidation of sulphanilamide during therapy. Am. J. Med. Sc., 1940, 199, 487.

16a. Rosenthal, S. M., and Bauer, H., Studies in chemotherapy. X. Colorimetric tests for aromatic hydroxylamines and for further oxidation products of aromatic amines. Their demonstration in the urine following sulfanilamide administration. $U$. S. Pub. Health Rep., 1939, 54, 1880.

b. Rosenthal, S. M., Experimental chemotherapy with sulfanilamide and related compounds. J. A. M. A., 1939, 113, 1710.

17. Feinstone, W. H., and others, The toxicity, absorption and chemotherapeutic activity of 2-sulfanilamido-pyridine (sulfadiazine). Bull. Johns Hopkins Hosp., 1940, 67, 427.

18. Mayer, R. L., and Oechslin, C., Antistreptococciques. Compt. Rend. Acad. d. Sc., Paris, 1937, 205, 181.

19. Long, P. H., Bliss, E. A., and Feinstone, W. H., Mode of action, clinical use and toxic manifestations of sulfanilamide. J. A. M. A., 1939, 112, 115 .

20. Ham, T. H., and Castle, W. B., Relation of increased hypotonic fragility and erythrostasis to the mechanism of hemolysis in certain anemias. Tr. A. Am. Physicians, 1940, 55, 127.

21a. Antopol, W., Applebaum, I., and Goldman, L., Two cases of acute hemolytic anemia with auto-agglutination following sulfanilamide therapy. J. A. M. A., 1939, 113, 488.

b. Myers, G. B., and Rom, J., Acute hemolytic anemia, hemoglobinuria and uremia following sulfanilamide. Ann. Int. Med., 1940, 14, 164.

c. Rosenthal, N., Personal communication. (One case.)

22. Landsteiner, $K$., The specificity of serological reactions. Thomas, Baltimore, 1936.

23. Mingoia, Q., Rocha, M., and Silva, Azoproteine solfanilamidiche e loro comportamento sierologico. Boll. d.'Ist. Sieroterap. Milanese, 1940, 19, 101.

24. Ottenberg, R., Clinical experiences with sulfanilamide therapy. N. Y. State J. Med., 1939, 39, 418.

25a. Lichty, J. A., Jr., Havill, W. H., and Whipple, G. H., I. Renal thresholds for hemoglobin in dogs. Depression of threshold due to frequent hemoglobin injections and recovery during rest periods. J. Exper. Med., 1932, 55, 603.

b. Monke, J. V., and Yuile, C. L., The renal clearance of hemoglobin in the dog. J. Exper. Med., 1940, 72,149 .

26. Gassmann, F. K., Uber die verteilung des gallenfarbstoffes in organismus. Ztschr. f. Klin. Med., 1930, $114,477$.

27. Broun, G. O., McMaster, P. D., and Rous, P., The relation between blood destruction and the output of bile pigment. J. Exper. Med., 1923, 37, 733.

28. Eilbott, W., Funktionsprüfung der leber mittels bilirubinbelastung. Ztschr. f. Klin. Med., 1927, 106, 529.

29. Gilligan, D. R., Altschule, M. D., and Katersky, E. M., Studies of hemoglobinemia and hemoglobinuria produced in man by intravenous injection of hemoglobin solutions. J. Clin. Invest., 1940, 20, 177.

30. Ravid, J. M., and Chesner, C., A fatal case of hemolytic anemia and nephrotic uremia following sulfapyridine administration. Am. J. M. Sc., 1940, 199, 380. 
31. Ottenberg, R., and Spiegel, R., The present status of chemical and infectious jaundice. (In preparation.)

32. Baker, S. L., and Dodds, E. C., Obstruction of the renal tubules during the excretion of haemoglobin. Brit. J. Exper. Path., 1925, 6, 247.
33. De Navasquez, S., The excretion of haemoglobin, with special reference to the "Transfusion" kidney. Jour. Path. and Bact., 1940, 51, 413.

34. Scudder, J., and others, Studies in blood preservation. J. A. M. A., 1939, 112, 2263. 